\title{
(a) OPEN ACCESS \\ Superior mesenteric artery syndrome in a patient with celiacomesenteric trunk
}

\author{
Swanit Hemant Deshpande (1) , Jenny Thomas, Roshan Chiranjeev, \\ Jayashri Sanjay Pandya
}

General Surgery, BYL Nair Charitable Hospital, Mumbai, Maharashtra, India

Correspondence to Dr Jayashri Sanjay Pandya; smruti63@hotmail.com

Accepted 11 February 2021

A Check for updates

(c) BMJ Publishing Group Limited 2021. Re-use permitted under CC BY-NC. No commercial re-use. See rights and permissions. Published by BMJ.

To cite: Deshpande $\mathrm{SH}$

Thomas J, Chiranjeev R,

et al. BMJ Case Rep

2021:14:e237132

doi:10.1136/bcr-2020-

237132

\section{SUMMARY}

Superior mesenteric artery (SMA) syndrome is an uncommon entity leading to compression of the duodenum between the aorta and the SMA. Normally the coeliac trunk and the superior mesenteric arteries have distinct origins from the abdominal aorta. The celiacomesenteric trunk (CMT) is the least frequently reported anatomic variation of all abdominal vascular anomalies. CMT denotes a common trunk of origin of the coeliac and superior mesenteric arteries. The coexistence of these anomalies has never been reported in the literature. We present a case of a 59-year-old man presenting with duodenal obstruction due to SMA syndrome with CMT. The aortomesenteric angle was 13 degrees and SMA-aorta distance was $8 \mathrm{~mm}$. Patient underwent a gastrojejunostomy. After an uneventful recovery, the patient has been symptom free for 1 year follow-up.

\section{BACKGROUND}

Superior mesenteric artery (SMA) in humans leaves the aorta at an acute and downward angle. ${ }^{1}$ Hence, there is a possibility of the third part of the duodenum to get compressed between the aorta posteriorly and the SMA anteriorly. $^{2}$ This compression has been termed as SMA syndrome, arteriomesenteric artery syndrome, chronic duodenal ileus, cast syndrome, mesenteric root syndrome, intermittent arteriomesenteric occlusion and Wilkie's syndrome. ${ }^{3}$ This is commonly attributed to the loss of the cushion of fat that normally surrounds the neurovascular pedicle. ${ }^{5}$ Hence, those who are presumed to be predisposed to the condition are those who are thin and those experiencing acute weight loss. ${ }^{67}$

The three main anterior branches of the abdominal aorta are the coeliac trunk, SMA and the inferior mesenteric artery. Celiacomesenteric trunk (CMT) leads to a common origin of coeliac trunk and SMA. CMT accounts for less than $1 \%$ of all abdominal vascular anomalies, and it is estimated to have an incidence of $0.25 \% .^{8-10}$ According to radiological studies, the incidence of SMA compressing the duodenum is reported as between $0.20 \%$ and $0.78 \% .^{11}{ }^{12}$ Incidence of SMA syndrome in the general population ranges between $0.0024 \%$ and $0.34 \% .{ }^{13}$

According to our review of the literature, SMA syndrome has never been reported in co existence with CMT.

\section{CASE PRESENTATION}

A 59-year-old man presented to surgical emergency with abdominal distension and repeated episodes of bilious vomiting for the past 12 hours. He had a pulse rate of $110 / \mathrm{min}$ and other vitals were stable. Nasogastric tube insertion drained $2 \mathrm{~L}$ of bilious gastric contents. The nasogastric drainage was followed by a significant decrease in the abdominal distension and also relief of symptoms.

A detailed history revealed that the patient was a farmer by occupation and belonged to a low socioeconomic class. He had a habit of chewing tobacco and was noted to have poor mouth opening. He gave a history of over-working and loss of significant weight over the past year.

He had lost $10 \%$ of body weight in the past 3 months. His body mass index had decreased from $21 \mathrm{~kg} / \mathrm{m}^{2}$ to $18.9 \mathrm{~kg} / \mathrm{m}^{2}$.

$\mathrm{He}$ had no comorbidities and no previous surgical history.

The patient was kept nil per oral for 2 days and was resuscitated with intravenous fluids.

\section{INVESTIGATIONS}

His laboratory investigations were within normal limits.

Contrast-enhanced CT scan of the abdomen was done with oral and intravenous contrast. It revealed a common origin of the coeliac trunk and SMA, a CMT. The CMT was seen branching into coeliac trunk and SMA. The coeliac trunk further branched into splenic artery, common hepatic artery and the left gastric artery (figures 1 and 2). Obstruction of the third part of the duodenum between the SMA and abdominal aorta with dilated proximal duodenum (figure 3). The aorto-celiaco-mesenteric angle was 13 degrees (figure 4) and SMA-aorta distance was $8 \mathrm{~mm}$ (figure 5).

\section{DIFFERENTIAL DIAGNOSIS}

Initially when the patient presented with features suggestive of gastric outlet obstruction and history of significant loss of weight in the recent past, the differential diagnosis of carcinoma of the stomach was considered. Highly specific findings on CECT scan helped clinch the diagnosis of SMA syndrome with CMT.

\section{TREATMENT}

The initial plan of management was to implement a conservative approach. Conservative management aimed to make the patient gain weight and improve 

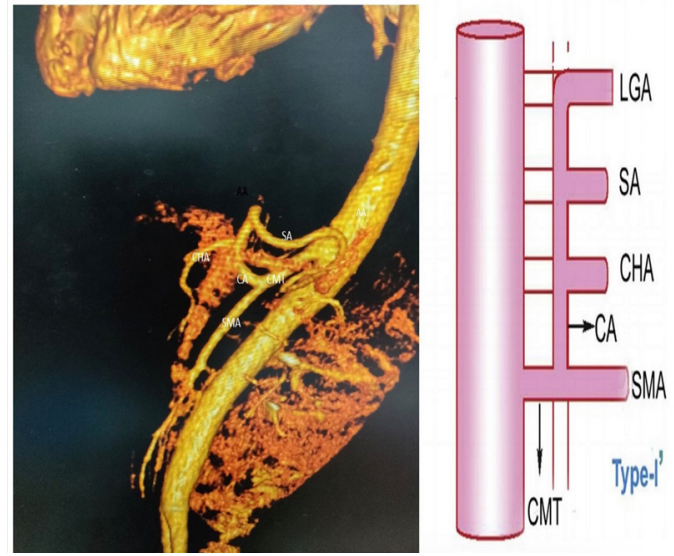

Figure 1 (Left half)- vascular reconstruction image of the CECT scan depicting the various branches of the celiaco-mesenteric trunk. (Right half)- pictorial depiction of Type I' of Morita classification (16). AA, abdominal aorta; $\mathrm{Ca}$, coeliac artery; $\mathrm{CECT}$, contrast-enhanced $\mathrm{CT}$; $\mathrm{CHA}$, common hepatic artery; CMT, celiacomesenteric trunk; LGA, left gastric artery; SA, splenic artery; SMA, superior mesenteric artery.

nutrition, as this would lead to an increment in the aortomesenteric angle.

Nasojejunal tube insertion was planned to bypass the site of obstruction. The patient was posted for upper Gastro-ntestinal (GI) scopy with nasojejunal tube insertion. The procedure could not be performed as the patient had poor mouth opening and the scope could not be negotiated even with fluoroscopy guidance.

Then it was planned that the patient will be given nasogastric feeding. The patient could not tolerate nasogastric feeds.

The conservative management was not successful. A decision was then taken to perform an exploratory laparotomy on the fourth day after admission. A midline skin incision was taken and the peritoneal cavity was exposed. There were no features suggestive of peritonitis or contamination. The third part of duodenum was compressed and the second part of the duodenum was grossly distended. There was no evidence of ischaemia of the intestine or colon. Due to grossly dilated duodenum, the decision was taken to perform gastrojejunostomy instead of

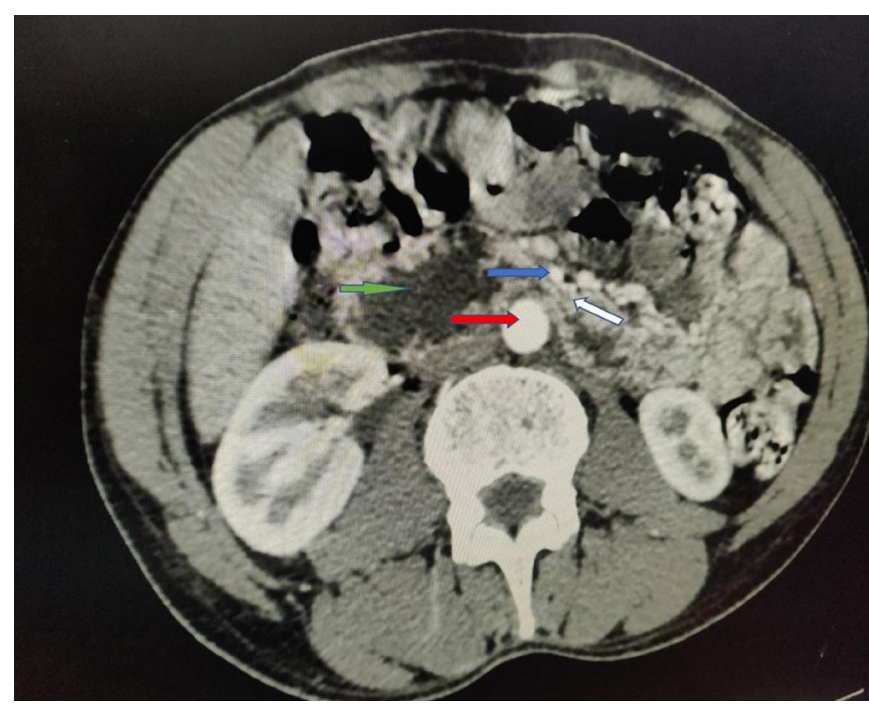

Figure 3 Axial section of the contrast-enhanced CT scan image of abdomen and pelvis depicting the compression of third part of the duodenum between the SMA and the abdominal aorta. The proximal part of the duodenum is dilated (White arrow-compressed third part of the duodenum, green arrow-the dilated proximal part, red arrow—abdominal aorta, blue arrow—superior mesenteric artery). SMA, superior mesenteric artery.

duodenojejunostomy. Stapled posterior gastrojejunostomy was done to bypass the compressed duodenum. An intraperitoneal drain was kept. The patient was extubated on the table and had an uneventful recovery.

\section{OUTCOME AND FOLLOW-UP}

The patient was discharged after suture removal on 10th postoperative day. He was advised to gain weight through a balanced diet and was advised to follow-up regularly. He failed to follow-up as he migrated to a distant village soon after the surgery. On regular telephonic conversations, he seemed to have symptomatic relief and could resume his work 1 month after the surgery. He says he has gained weight and has been asymptomatic over the past year.

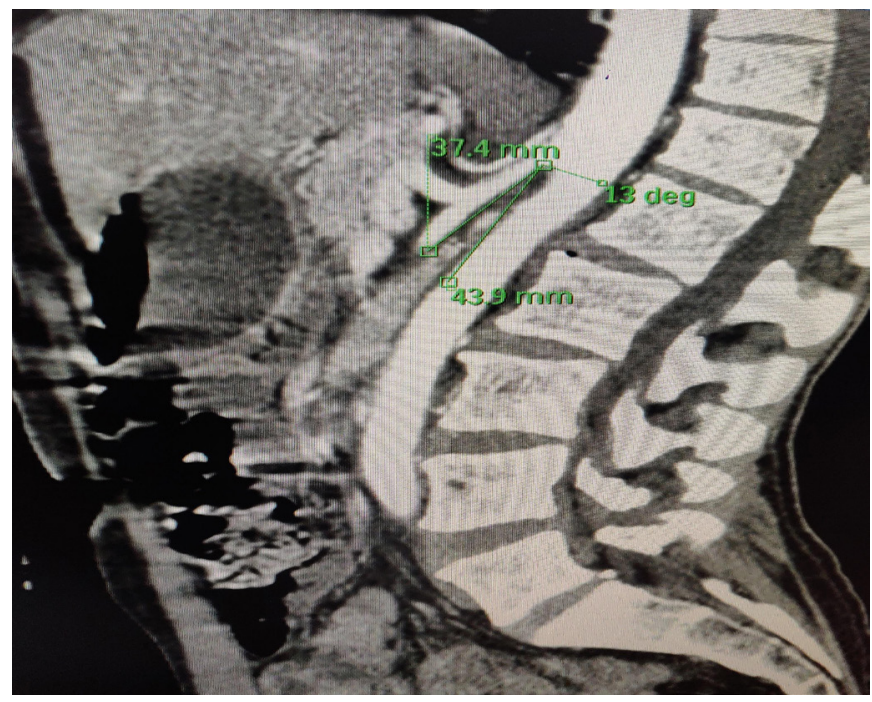

Figure 4 Sagittal section of contrast-enhanced CT scan of the abdomen and pelvis - depicting the the aorto-CMT angle of 13 degrees. CMT, celiacomesenteric trunk.
Figure 2 Unlabelled vascular reconstruction image of the contrastenhanced CT scan of abdomen-depicting the various branches of the celiaco-mesenteric trunk. 


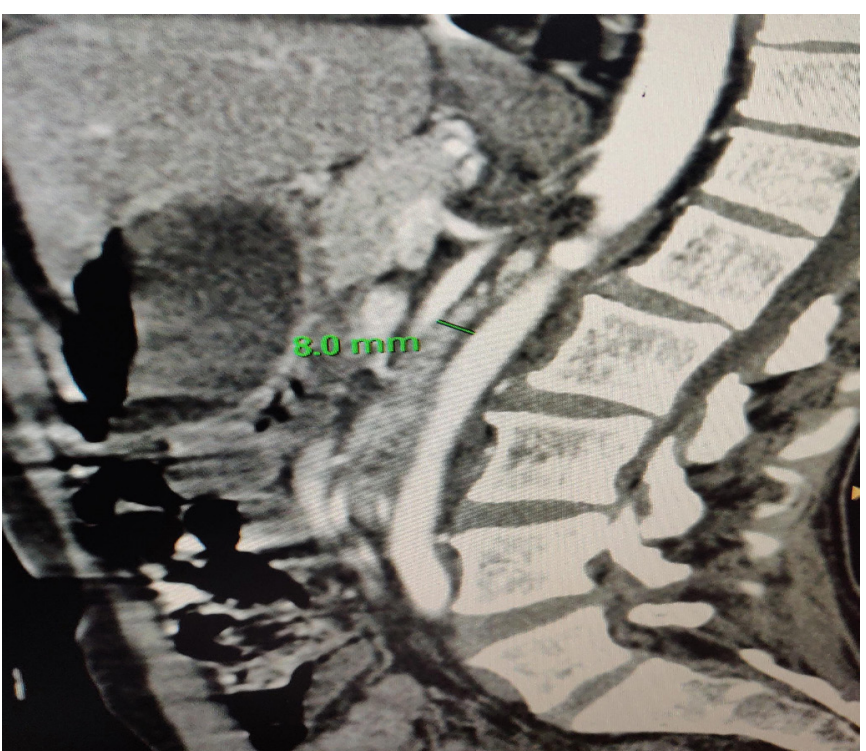

Figure 5 Sagittal section of contrast-enhanced CT scan of the abdomen and pelvis-depicting the distance between aorta and the mesenteric artery $(8 \mathrm{~mm})$ and the compressed duodenum between the two.

\section{DISCUSSION}

The occurrence of CMT is a rare entity. ${ }^{14} 15$ Our patient had a common origin of CMT with all the three branches of coeliac artery arising from the CMT. In embryonic life, normally the 10th and 13th vitelline arteries develop into the coeliac and superior mesenteric arteries, respectively. Initially, these vitelline arteries are connected by a ventral longitudinal anastomosis. Normally the 11th and 12th vitelline arteries disappear, while the 10th vitelline along with longitudinal anastomosis gives rise to coeliac artery and its three branches. Embryologically, therefore, the occurrence of CMT can be explained by the regression of the 10th root and persistence of ventral anastomosis between 12 th and 13 th roots. ${ }^{16}$

The CMT is usually an incidental finding. It may be associated with aneurysms, occlusion and stenosis resulting in severe mesenteric ischaemia. ${ }^{17}$ There has been a recent case report of thrombosis of the CMT leading to widespread ischaemia and death. ${ }^{18}$ CMT leads to an intrinsic loss of CA-SMA collateral circulation, which is important in protecting against mesenteric ischaemia. This leaves a large segment of bowel with one dominant vascular feed. ${ }^{19} 20$

According to our review of the literature, this is the first reported case of SMA syndrome reported with the concurrent existence of CMT. It is unclear whether this anatomic variation predisposed the SMA to cause the compression of the duodenum.

Most recommend a conservative approach as the first line of therapy for SMA syndrome. ${ }^{21}$ Such measures are often multidisciplinary and are aimed at replenishing the mesenteric fat stores and decompressing the third part of the duodenum. ${ }^{22}$ Postprandial positional changes, such as knee-chest position, tend to widen the aortomesenteric angle. This partially relieves duodenal obstruction. ${ }^{23}$ Drainage with the nasogastric tube can be continued in selected cases of SMA syndrome. ${ }^{21}$

Surgery is preferred in patients who fail to respond to conservative management. Both laparoscopic and open surgical procedures such as gastrojejunostomy, duodenojejunostomy or sectioning of the wide division of the ligament of Treitz (Strong's procedure) have been used. Most surgeons prefer

\section{Patient's perspective}

Someone who has never been admitted to the hospital, I was very scared to have been informed about the need for a surgery. I felt a lot better after the surgery, as the vomiting had stopped. I cannott wait to get back to work as my family depends on me. I have been told to increase my diet and that is going to be a priority. I want to thank all the doctors and nurses who were involved in making me feel better. Patient himself (translated from Marathi).

\section{Learning points}

- Superior mesenteric artery (SMA) syndrome should be a differential diagnosis in all cases of gastric outlet obstruction.

- Surgical treatment of SMA syndrome is effective when conservative treatment fails.

- Gastrojejunostomy can be done when there is significant dilation of duodenum instead of duodenojejunostomy.

- Vascular anomalies of the abdominal aorta and its branches are rare but can be ruled out by careful observation on CT scan imaging and considering them as a possible differential diagnosis in cases with narrow aorto-mesenteric angle.

duodenojejunostomy as the procedure of choice for SMA syndrome. ${ }^{24}$ Duodenojejunostomy is more physiological, and, unlike gastrojejunostomy, there are fewer chances of jejunal ulceration.

Gastrojejunostomy may be ideal when patients with SMA syndrome present with severe duodenal dilatation. ${ }^{25}$ Possible complications of gastro-jejunostomy include anastomotic leak, stenosis and jejunal ulcerations.

In the current case, the second part of duodenum was significantly dilated and hence gastrojejunostomy was done. The patient had an uncomplicated recovery and has been asymptomatic for 1 year after the surgery.

Twitter Swanit Hemant Deshpande @swanitdeshpande

Contributors SHD-conceptualised the idea, compiled the data and images, drafted the manuscript and was assisting surgeon in the mentioned surgery. JT—review of literature, edited the images. RC—edited the manuscript, operating surgeon in the mentioned surgery in the case report. JSP_-final editing of the manuscript, edited the review of literature.

Funding The authors have not declared a specific grant for this research from any funding agency in the public, commercial or not-for-profit sectors.

Competing interests None declared.

Patient consent for publication Obtained.

Provenance and peer review Not commissioned; externally peer reviewed.

Open access This is an open access article distributed in accordance with the Creative Commons Attribution Non Commercial (CC BY-NC 4.0) license, which permits others to distribute, remix, adapt, build upon this work non-commercially, and license their derivative works on different terms, provided the original work is properly cited and the use is non-commercial. See: http://creativecommons.org/ licenses/by-nc/4.0/

\section{ORCID iD}

Swanit Hemant Deshpande http://orcid.org/0000-0003-3294-9520

\section{REFERENCES}

1 Moskovich R, Cheong-Leen P. Vascular compression of the duodenum. J R Soc Med 1986;79:465-7.

2 Welsch T, Büchler MW, Kienle P. Recalling superior mesenteric artery syndrome. Dig Surg 2007;24:149-56. 
3 Lundell L, Thulin A. Wilkie's syndrome--a rarity? Br J Surg 1980;67:604-6.

4 Laffont I, Bensmail D, Rech C, et al. Late superior mesenteric artery syndrome in paraplegia: case report and review. Spinal Cord 2002;40:88-91.

5 Adson DE, Mitchell JE, Trenkner SW. The superior mesenteric artery syndrome and acute gastric dilatation in eating disorders: a report of two cases and a review of the literature. Int J Eat Disord 1997;21:103-14.

6 Burrington JD, Wayne ER. Obstruction of the duodenum by the superior mesenteric artery--does it exist in children? J Pediatr Surg 1974;9:733-41.

7 Froese AP, Szmuilowicz J, Bailey JD. The superior-mesenteric-artery syndrome: cause or complication of anorexia nervosa? Can Psychiatr Assoc J 1978;23:325-7.

8 Michels NA, Siddharth P, Kornblith PL, et al. Routes of collateral circulation of the gastrointestinal tract as ascertained in a idssection of 500 bodies. Int Surg 1968;49:8-28.

9 Michels NA. Blood supply and anatomy of the upper abdominal organs with a descriptive atlas. Philadelphia: Lippincott, 1955.

10 Fontaine R, Pietri J, Tongio J, et al. [Angiographic study of the anatomical variations of the hepatic arteries based on 402 specialized examinations]. Angiology 1970;21:110-3.

11 Anderson JR, Earnshaw PM, Fraser GM. Extrinsic compression of the third part of the duodenum. Clin Radiol 1982;33:75-81.

12 Rosa-Jiménez F, Rodríguez González FJ, Puente Gutiérrez JJ, et al. Duodenal compression caused by superior mesenteric artery: study of 10 patients. Rev Esp Enferm Dig 2003;95:485-9.

13 Lee CS, Mangla JC. Superior mesenteric artery compression syndrome. Am J Gastroenterol 1978;70:141-50.

14 Winston CB, Lee NA, Jarnagin WR, et al. Ct angiography for delineation of celiac and superior mesenteric artery variants in patients undergoing hepatobiliary and pancreatic surgery. AJR Am J Roentgenol 2007;189:W13-19.
15 Wang Y, Cheng C, Wang L, et al. Anatomical variations in the origins of the celiac axis and the superior mesenteric artery: MDCT angiographic findings and their probable embryological mechanisms. Eur Radiol 2014;24:1777-84.

16 Ramesh Babu CS, Joshi S, Gupta KK, et al. Celiacomesenteric trunk and its variants a multidetector row computed tomographic study. J Anat Soc India 2015;64:32-41.

17 Addicott B, Nguyen M, Pedro P. Common celiacomesenteric trunk presenting with mesenteric ischemia: 2 case reports with a review of literature. J Hosp Med 2013;8:915

18 Lovisetto F, Finocchiaro De Lorenzi G, Stancampiano P, et al. Thrombosis of celiacomesenteric trunk: report of a case. World J Gastroenterol 2012;18:3917-20

19 Lee $V$, Alvarez MD, Bhatt S, et al. Median arcuate ligament compression of the celiomesenteric trunk. J Clin Imaging Sci 2011;1:8.

20 Chaiwatcharayut W, Lekah A, Kurklinsky A. Celiacomesenteric trunk as a cause of median arcuate ligament syndrome. J Med Ultrasound 2013;21:39-42.

21 Welsch T, Büchler MW, Kienle P. Recalling superior mesenteric artery syndrome. Dig Surg 2007;24:149-56.

22 Shiu J-R, Chao H-C, Luo C-C, et al. Clinical and nutritional outcomes in children with idiopathic superior mesenteric artery syndrome. J Pediatr Gastroenterol Nutr 2010;51:177-82.

23 Gersin KS, Heniford BT. Laparoscopic duodenojejunostomy for treatment of superior mesenteric artery syndrome. JSLS 1998:2:281-4.

24 Jain R. Superior mesenteric artery syndrome. Curr Treat Options Gastroenterol 2007:10:24-7.

25 Yang WL. [Surgical treatment of superior mesenteric artery syndrome]. Zhonghua Wai Ke Za Zhi 1991;29:421-3.

Copyright 2021 BMJ Publishing Group. All rights reserved. For permission to reuse any of this content visit https://www.bmj.com/company/products-services/rights-and-licensing/permissions/

BMJ Case Report Fellows may re-use this article for personal use and teaching without any further permission.

Become a Fellow of BMJ Case Reports today and you can:

- Submit as many cases as you like

- Enjoy fast sympathetic peer review and rapid publication of accepted articles

- Access all the published articles

Re-use any of the published material for personal use and teaching without further permission

Customer Service

If you have any further queries about your subscription, please contact our customer services team on +44 (0) 2071111105 or via email at support@bmj.com.

Visit casereports.bmj.com for more articles like this and to become a Fellow 